\title{
Using patents to mislead rivals
}

\author{
Corinne Langinier*
}

December 2003

\begin{abstract}
Recent surveys report that firms claim they do not rely heavily on patents in order to appropriate a return on their innovation. Yet, firms do patent, as indicated by the large number of patents that are granted. This paper offers a possible resolution to this puzzle.

It takes a simplified version of a duopoly innovation race, and studies the patenting decision of an innovator who has private information about the improvability of her innovation. In this setting, it is shown that a firm may use the patenting decision to mislead her rival. Under symmetric information, research can be stimulated but not disclosed. However, under asymmetric information, disclosure is more likely even though the incentive to do research may be weakened.
\end{abstract}

Keywords: patent, innovation race, improvable innovation, asymmetric information. JEL Classification 031, L1.

\footnotetext{
${ }^{*}$ Department of Economics, Iowa State University, Ames. langinie@iastate.edu I would like to thank Joydeep Bhattacharya, Isabelle Brocas, Claude Crampes, David Encaoua, Philippe Marcoul, David Pérez Castrillo, Michel Poitevin, Cecil Quillen, Jennifer Reinganum, David Sevy, two anonymous referees, the participants of the Haas Business School Innovation Workshop in Berkeley, and the participants of seminars at Concordia University and UQAM for their comments on a previous version of the paper. All errors are naturally mine.
} 


\section{Introduction}

Surveys show that firms claim not to rely heavily on patents to (directly) appropriate the returns from their innovation (Cohen, Nelson, and Walsh 2000). However, firms do patent, and we have witnessed an unprecedented jump in U.S. and Canadian patenting in 1998. This can be explained by the important reforms in the U.S. and the Canadian patent systems (Gallini 2002, Gallini, Putnam and Tepperman 2001). ${ }^{1}$ However, there may be other reasons, as well. It may be that firms not only desire to appropriate the return on their innovation directly (for instance, by collecting royalties from firms using the more efficient invention), but use patents in other ways, for the same purpose.

More often than not, legal counsel provided to firms concerned with their Intellectual Property Rights (IPRs) is to "patent their innovations ASAP, as soon as possible." The underlying reason is that "competitors are working on the same idea, and thus whoever files an application first has major advantages over others who file later." ${ }^{2}$ A natural counter argument to this simplistic line of thinking is that given that her innovation can be improved upon, an innovator may prefer to avoid the disclosure of information that follows a patent in order to keep her competitive advantage. Indeed, firms typically want to keep most inventions secret during the course of their development. Hence, the "ASAP" advice appears not to be always useful. A natural question that arises in this context is the following: when does an innovator patent her discovery immediately and when does she keep it secret whilst improving upon it?

The decision to wait and the decision to patent have each their own drawbacks. On the one hand, even though a patent gives temporary monopoly power to the innovator, it discloses information, and therefore facilitates rapid catch up by competitors. Moreover, if the innovation can be improved upon, the patent allows competitors to do so without undertaking all of the research already completed by the innovator. All firms are then placed on an equal footing from where they may improve upon the innovation, an improvement that may eventually invalidate

\footnotetext{
${ }^{1}$ U.S. patent protection has $(i)$ extended patent protection to new subject matter (starting with the Diamonds v. Chakrabarty case, 1980); (ii) given greater power to patentholders in infringement lawsuits (creation of a specialized court); (iii) lengthened the term of patents (now 20 years).

${ }^{2}$ Advice given by P. Kelly, in the book by Lechter (1995), page 226.
} 
the original patented innovation. On the other hand, the decision to wait entails risk; even if it slows down competitors, it is possible that one of them may discover the yet non-patented innovation and decide either to exploit it or to patent it himself. If the system in force is "firstto-invent," as is the case in the U.S., the patentholder can claim that she invented the innovation first, and then claim the right to share in its exploitation. However, in Canada and many other countries, the first innovator cannot even claim that she was the first inventor ("first-to-file" rule). Therefore, the decision to patent an improvable innovation must be challenged against the decision to keep it secret.

Another issue of great importance is the following: what if there is asymmetric information on whether the innovation can be improved upon. For instance, if the leader has more information concerning the innovation than her competitor (e.g., whether it can be improved or not), she may use this information strategically. The less-informed firm can then try to infer information from observing the leader's decision. Thus, the patenting (or waiting) decision can be potentially used by the leader as a strategy to mislead her competitors.

There is considerable evidence that firms use "decoy patents" to direct competitors into unprofitable fields of research: "An offensive protection (bluff) is part of the game; for instance decoy patents are common in order to mislead competitors and make them believe that we are doing research in an unexpected area" (translation of a quotation in L'entreprise (October 1995), C. Pascaud and J.L. Piotraut, Industrial Innovation). ${ }^{3}$ In the petroleum industry, it is common practice to patent numerous inventions, one good one in a flood of bad inventions. ${ }^{4}$

In spite of these glaring examples from the real world, little theoretical attention has been

\footnotetext{
${ }^{3}$ It is very difficult to empirically distinguish the practice of patenting numerous misleading inventions from "drilling a lot of dry holes" to increase the probability of finding a valuable invention.

${ }^{4}$ The pharmaceutical industry has appealing examples of the strategic use of information. For instance, in the mid 1980s, Genentech and Ely Lilly were working on the same project for the pharmaceutical human Growth Hormone $(\mathrm{hGH})$ to treat children with a deficiency of that hormone. During the time Genentech was improving this hormone (a version with one less amino acid, afterwards called met-less hGH), they chose not to patent and disclose information, thereby keeping their competitive advantage. Subsequently they behaved strategically: they published four or five ways of accomplishing the same engineering task, without divulging the most efficient and actually used ones. After that, they made a mistake, patenting one part of the improvement too early; thus, Ely Lilly caught up with them and was allowed protection for a better improvement (See McKelvey 1996).
} 
devoted to the study of patents as means to mislead competitors (Horstmann, MacDonald and Slivinsky 1985, Crampes and Langinier 1998). There is however a burgeoning empirical literature concerned with the strategic management of patent portfolios (Hall and Ham-Ziedonis 2001). Even though few contributions deal with the use of patents to mislead competitors, patents have been extensively studied in the economic literature as the patenting decision has a non-trivial impact on the pace of innovation. ${ }^{5}$

The purpose of this paper is to provide a simple theoretical framework within which a firm's decision to patent or wait can be meaningfully explored. We consider innovations that can or cannot be improved, under both symmetric and asymmetric information on whether, indeed, the innovation can be improved upon. Our paper focuses primarily on the private incentives to patent. We study how strategic patenting decisions can, under certain circumstances, induce the competitor to exit the race. The model is closest in spirit to Horstmann, MacDonald and Slivinsky (1985), in which an innovator has private information about the profit available to competitors. In their setting, the patent system can transmit private information from the innovator to competitors, and, patenting an innovation may signal that the invention is easy to duplicate. They show that patenting occurs less often as it becomes a more reliable signal of the profitability of the imitation. In our model, on the contrary, the patenting decision may signal that the innovation cannot be improved upon.

We consider a simplified version of a duopoly patent race, where the date on which a discovery occurs is known, but the identity of the one who makes it is uncertain. At the outset, the leader has discovered an innovation, and is to decide either to patent the innovation or to keep it secret while attempting to improve on it. We assume that the follower knows that an innovation has

\footnotetext{
${ }^{5}$ The government's choice on whether or not to grant patents on every improvement will change the pace of innovation as will the system considered, namely "first-to-file" versus "first-to-invent" (Scotchmer and Green 1990). Takalo and Kanniainen (2000) argue that patents slow technological progress, and they consider that the initial investment in R\&D only leads to a future option. The idea of option originated with Pakes (1986) who states that the renewal of a patent gives the option to keep it in force the following year. They show that the patenting decision may be postponed if the project is not too difficult, if the coverage of the patent protection is small and if the cost of the patent is relatively high. The cumulative nature of innovation has also been analyzed (O'Donoghue, Scotchmer and Thisse 1996, Chang 1995, O'Donoghue 1998), as well as the problems linked to the patentability of improvements (van Dijk 1996) or applications (Matutes, Regibeau and Rockett 1996).
} 
been discovered. He observes the decision of the leader, and then has to decide to stay in the race or to exit. The races differ depending on whether or not the leader has patented her innovation. If she has patented, then both firms attempt to improve upon the existing innovation. However, because of the patent, the follower is prevented from exploiting the innovation, while the leader can. We posit that it is not sufficient to simply be aware of the details (i.e., the blueprints) of the innovation in order to improve on it. Rather, developing the innovation may require some specific skills or know-how that are costly to acquire. ${ }^{6}$ On the other hand, if the leader has kept her innovation secret, the follower would have to first catch up with the leader, and if successful, try to improve on it.

However, this is only one side of the story. Indeed, all innovations do not constitute promising research leads, and it may turn out that the innovation is non-improvable. Ex ante, the leader is the only party that is truly aware of whether or not this is the case, as it was her discovery to begin with. Nevertheless, new skills may have been acquired in the process of discovery which may find applications in new research programs. We assume that even when the innovation cannot be improved upon, the leader invests in another research program. If the leader has patented the innovation, it is costly for the follower to acquire the technical details behind it. ${ }^{7}$ On the other hand, if the leader has suppressed her innovation, the follower must first catch up with her before he can realize that the innovation cannot be improved and start another research program.

Our main results are as follows: under symmetric information, the leader discloses her innovation less often when it can be improved upon; but the research is stimulated (even though it is a duplication of the first innovation's research effort), as the follower stays in the race more often. Things are quite different when the leader has more information concerning the improvability of the innovation than the follower. This latter has only prior beliefs, and the leader behaves strategically in order to mislead her competitor. For a certain constellation of

\footnotetext{
${ }^{6}$ Choi (2001) considers a problem of licensing in which he notices that in practice, information is costly to transfer to other firms in the case of licensing. In the same vein, we consider that information is costly to acquire when a patent has been granted.

${ }^{7}$ That is, the process of realizing that an innovation cannot be improved upon may be prohibitively costly. The follower can start another research program, but it may prove more difficult to make it profitable.
} 
parameters she suppresses her innovation under symmetric information whereas she patents it under asymmetric information (only if the follower has low prior beliefs about its improvability); she randomizes her decision when his prior beliefs are higher. Therefore, under asymmetric information, disclosure and patenting are more likely than under symmetric information, but the research intensity may be lower since the follower exits more often. When the follower observes that the innovation has been kept secret, it informs him that the innovation can be improved upon, while the observation of a patent gives no information. Thus, the leader may expect the follower to stay in the race when the innovation cannot be improved upon, leading the follower to pursue an unprofitable research avenue. This kind of patent can be seen as a decoy. ${ }^{8}$

The rest of the paper is organized as follows. The model is presented in Section 2, and the payoffs of the firms are computed. In Section 3 we determine the decision to patent and the decision to stay under symmetric information. We go on to analyze the case of asymmetric information and derive equilibria in pure and mixed strategies in Section 4. Section 5 presents results from a comparative statics analysis while Section 6 concludes.

\section{The Model}

We consider a two-firm model of product innovation and improvement where the innovation must be completed before starting the improvement phase. At the outset, firm $A$ (the leader) has made the innovation, whereas firm $B$ (the follower) has not but is fully aware that the leader has made it. Having done the innovation, firm $A$ has private information concerning its improvability, ${ }^{9}$ whereas firm $B$ has only prior beliefs about it. For simplicity, we consider only the two polar cases, one where the innovation can (cannot) be improved. The innovation cannot be improved upon if, for instance, it is prohibitively costly to do so. Hence, there are only two states of nature, $\Omega=\{h, l\}$, where $h$ corresponds to an improvable innovation and $l$ to a non-improvable innovation. Let $\rho$ denote the probability that the innovation can be improved.

\footnotetext{
${ }^{8}$ The idea of a decoy is closely related to a model of feint developed by Hendricks and McAfee (2003). In a game of feint the leader, who can be of two types (e.g., good or bad), wants to convince the follower that she is the opposite type thereby misleading her competitor.

9 "Having done the original work, the inventor is likely to be better positioned than everyone else to see certain of the developmental opportunities and the solutions," Merges and Nelson (1994).
} 
The timing of the game is as follows.

First, the leader has to decide either to patent her innovation $(p)$, or to keep it secret $(s) ; d_{A}: \Omega \rightarrow S_{A}=\{p, s\}$ where $d_{i}$ is the decision of firm $i=A, B$ and $S_{i}$ the set of strategies. In any case, she keeps investing in research, either to improve upon her innovation or to make a new discovery.

Second, the follower observes the decision of the leader and then decides whether or not to continue investing in research, i.e., stay in the race or exit, $d_{B}: S_{A} \rightarrow S_{B}=\{$ stay, exit $\}$. If the leader has patented her innovation, the innovation becomes partly available because of the obligatory public disclosure of any patent. It is only partly available because the follower will have to acquire know-how (materials plants, for instance) or, more generally, the knowledge that is not included in the patent description, to be completely aware of the innovation. ${ }^{10}$ If the follower decides to stay in the race, he has to pay a fixed cost, $F$, to acquire this nonrevealed information. After incurring this cost, he becomes fully aware of the improvability of the innovation. In other words, only after $F$ is sunk does the follower learn whether the innovation is improvable or not. If the innovation has been kept secret, and if the follower decides to stay in the race, he must first catch up with the leader (i.e., discover the innovation) and then, if possible, try to improve upon it.

We assume that once both firms have made their decisions, and whenever firm $B$ stays in the race, they are engaged in a (simplified) race where each firm spends $c$ per unit of time. ${ }^{11}$ It is either an asymmetric race, where firm $B$ searches for the innovation whilst firm $A$ tries to improve upon it, if possible (when the innovation has been kept secret), or it is a symmetric race if they both try to improve upon the innovation. The latter case obtains either when firm $A$ has patented the innovation, or when she has kept it secret, but firm $B$ has caught up with her. If firm $B$ catches up with firm $A$, he may choose to patent his discovery $\left(d_{B / s}=p\right)$. If

\footnotetext{
${ }^{10}$ In other words, a patent description does not give complete knowledge of the technology (e.g., the background knowledge that researchers accumulate with their research is also important). The leader may even decide to license the know-how.

${ }^{11}$ We make the simplistic assumption that decisions and investments are not made at the same time. For instance, it could be the case that the R\&D specialists of the firm decide whether to patent or not, and then decide to invest starting when the budget becomes available.
} 
he decides not to patent it, firm $A$ could conceivably decide to patent it later and the strategy to suppress can then be seen as a delay strategy. For simplicity, we set the parameters of the model such that if the leader does not patent in the first place, she does not patent afterwards.

In this simplified model of race, there is no uncertainty about the date at which a discovery occurs (either the innovation or the improvement), and we abstract from research effort decisions. Let $t_{1}$ denote the first date at which a discovery occurs, either in the asymmetric race when the innovation has been kept secret $\left(d_{A}=s\right)$, or in the symmetric race when the innovation has been patented $\left(d_{A}=p\right)$. Furthermore, if $d_{A}=s$ and the follower has caught up with the leader at date $t_{1}$ we need to specify another date, say $t_{2}$, on which the improvement or a new discovery will occur. In these simple races, even though the dates are known with certainty, the identity of the winner (of either race) is not. With probability $p_{1} \in[0,1]$, the leader makes the discovery first, and with probability $\left(1-p_{1}\right)$ it is the follower. If the innovation has been kept secret and the follower discovers it, both firms are engaged in a symmetric improvement race (or a new innovation race if the innovation cannot be improved upon). Then, with probability $p_{2} \in$ $[1 / 2,1]$, the leader makes the improvement (or new discovery) first, and with the complementary probability, the follower is first. The restriction on $p_{2}$ (i.e., $p_{2} \geq 1 / 2$ ) gives the leader a little advantage in the second race, and insures that if she has not patented first, she will not patent afterwards. $^{12}$

To complete the description of the model, we make the following assumptions. The patent system is assumed to be "first-to-file:" the first to apply for the patent and not necessarily the first

\footnotetext{
${ }^{12}$ In a more complex patent race, each firm should choose his or her own intensity of research (variable $c$ that is fixed here). A more realistic (but more complicated and not necessarily tractable) model should consider two features both of which are well emphasized in the patent race literature. See Reignanum (1989) for a survey on patent races. First, neither firm knows when the innovation will occur; this is modeled by a random discovery date that depends on both firms' level of investments. Second, neither firm knows who will make the discovery first. These research intensities should influence the date at which both the innovation and improvement will be discovered, as well as the identity of the winner. None of these effects are at stake here, as the intensity of research is fixed. See end of Section 5 for details on these complex patent races.
} 
to innovate gets the patent. ${ }^{13}$ The patent on the innovation guarantees a perfect monopoly, ${ }^{14}$ the pursuant discovery of the improvement invalidates the innovation, and the patent life is infinite.

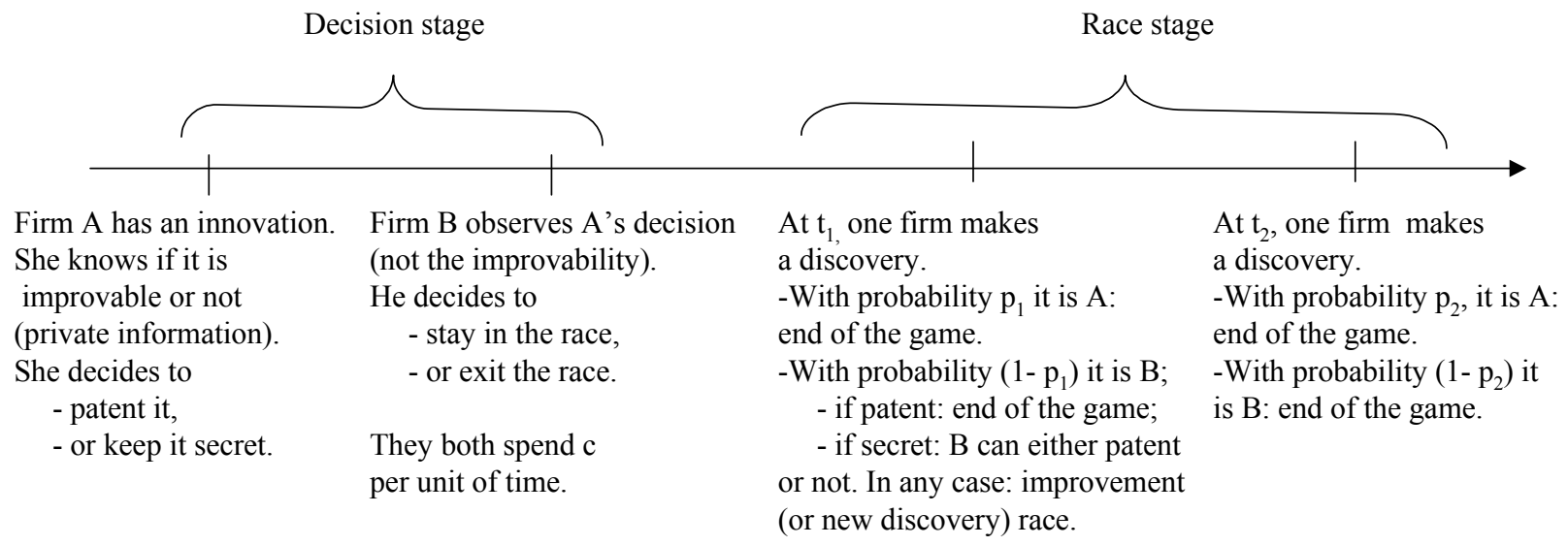

Timing of the game

To summarize, the timing of the game is as follows. There are two stages: a decision stage and a race stage. In the decision stage, the leader first decides either to patent her innovation or not (i.e., $d_{A} \in S_{A}$ ). Second, the follower observes her decision, and then decides either to stay in the race or to exit (i.e., $d_{B} \in S_{B}$ ). Whatever his decision, the leader always invests to improve or to make a new innovation. If $d_{B}=$ exit, the leader is assured of making the improvement or finding a new innovation. However, if $d_{B}=$ stay, firms are engaged in a symmetric race if $d_{A}=p$, or in an asymmetric race if $d_{A}=s$. In any case, firms spend $c$ per unit of time, and at date $t_{1}$, either the leader makes the discovery (with probability $p_{1}$ ) and then the game ends, or the follower does (with the complementary probability) and, depending on the race, the game

\footnotetext{
${ }^{13}$ In the "first-to-invent" system, as long as the initial inventor can prove that she made the invention first, she can exploit her innovation, even if patented by someone else. In this paper we consider the more dramatic case where the first innovator cannot even claim the exploitation.

${ }^{14}$ For both innovation and improvement, we assume that the patent coverage is perfect and that imitation is not possible. This is a traditional assumption in the patent literature, although it is well known that the patent protection is imperfect. See Aoki and $\mathrm{Hu}$ (1999) and Crampes and Langinier (2002) for an analysis with imperfect patent protection.
} 
does not necessarily end. If $d_{A}=p$, this is the end of the game. Otherwise, if $d_{A}=s$, and the follower has caught up with the leader, both firms compete to make the possible improvement. However, the follower is to decide whether to patent or not his discovery $\left(d_{B / s} \in S_{A}\right)$.

In the rest of the section and before solving the game in Sections 3 and 4, we detail the payoffs of the firms when the innovation is improvable and when it is not.

\subsection{Payoffs in the Case of an Improvable Innovation}

We first determine the payoffs of the two firms when the innovation can be improved upon.

If the leader patents her innovation $\left(d_{A}(h)=p\right)$ she obtains a flow of payoff $\Pi_{1}$ in each time period during the improvement phase. As soon as one of the firms discovers and patents the improvement, it invalidates the patented innovation and the firm who makes the improvement will get a flow of payoff $\Pi_{2}$ during an infinite period of time. On the other hand, if the leader keeps her innovation secret $\left(d_{A}(h)=s\right)$, she does not exploit it during the improvement phase, and thus she earns no return from the product innovation. It is clear that if she decides to exploit her innovation while it is not protected by a patent, it would be equivalent to having disclosed the information about the innovation without enjoying any temporary monopoly power. Therefore, the follower would easily catch up because of reverse engineering, and the leader would lose the benefit of being ahead. She is thus better off not exploiting it while it is kept secret. Nevertheless, even though she does not get any payoff during the improvement phase, if she makes the discovery first (i.e., the improvement), she gets a flow of payoff $\Pi_{12}$ during an infinite period of time for patenting the improved innovation. However, if the follower catches up with her and makes the innovation (he is first in the race), she still has a chance to make the improvement as both firms compete for the improvement.

We make the plausible assumption that the original innovation has little value compared to any patented improvement. In other words, the original patent contributes little value compared to the improvement. ${ }^{15}$ Formally, $\Pi_{1}<\min \left(\Pi_{2}, \Pi_{12}\right)$.

\footnotetext{
${ }^{15}$ This is, for instance, the case with gene patents that have very little value by themselves, but lead to highly valuable improvements. It can also be the case with laser technology that is tied to the value of follow-on applications (for other examples, see Green and Scotchmer 1995).
} 
Most of our discussion of the patenting decision will be a function of $\Pi_{12}$ and $\Pi_{2}$ and we do not specify a priori any relationship between those payoffs. At first, it is tempting to think that the (discounted) sum of the payoffs from patenting the innovation $\left(\Pi_{1}\right)$ and the improvement $\left(\Pi_{2}\right)$ would equal the payoff from patenting the improved innovation $\left(\Pi_{12}\right)$. However, this is not necessarily the case. Indeed, it can happen that the introduction of the innovation boosts the demand for the improvement and therefore $\Pi_{12}<\Pi_{2}$ (e.g., when consumers first get used to the innovation before buying the improvement. For instance, one might think of a buy-back guarantee where the firm is assured to have a captive base of consumers). Or, it can be the case that the introduction of the innovation is at too premature a stage in the process, and does not do well in the subsequent improvement, and thus $\Pi_{12}>\Pi_{2}$ (or for instance, due to the cost duplication of launching, or advertising the innovation and the improvement, it is worthwhile to wait for launching a unique improved innovation). In short, $\Pi_{12}$ can be bigger, equal or smaller than $\Pi_{2}$.

After having defined the different payoff flows, we now determine the (expected discounted) payoffs of each firm depending on the initial decisions made. If the follower exits the race, his payoff is null and, the leader gets

$$
V_{p}^{m}=\int_{0}^{t_{1}}\left(\Pi_{1}-c\right) e^{-r t} d t+\int_{t_{1}}^{+\infty} \Pi_{2} e^{-r t} d t=\frac{1}{r}\left[\delta_{1}\left(\Pi_{1}-c\right)+\Pi_{2}\left(1-\delta_{1}\right)\right]
$$

if she patents the innovation, and $V_{s}^{m}=\frac{1}{r}\left[-c \delta_{1}+\Pi_{12}\left(1-\delta_{1}\right)\right]$ if she keeps it secret; where $\delta_{1} \equiv 1-e^{-r t_{1}}$ when the discovery is made at date $t_{1}, r$ is the discount rate, the superscript $m$ stands for monopoly and the subscript $p$ (respectively $s$ ) stands for patent (respectively for secret).

If the follower stays in the race after a patent $\left(d_{B}(p)=\right.$ stay $)$, each firm's payoff is

$$
\begin{aligned}
V_{p}^{A} & =\frac{1}{r}\left[\delta_{1}\left(\Pi_{1}-c\right)+p_{1} \Pi_{2}\left(1-\delta_{1}\right)\right] \text { for firm } A, \\
\text { and } V_{p}^{B} & =\frac{1}{r}\left[-c \delta_{1}+\left(1-p_{1}\right) \Pi_{2}\left(1-\delta_{1}\right)\right]-F \text { for firm } B,
\end{aligned}
$$

where $p_{1}$ (respectively $1-p_{1}$ ) is the probability that firm $A$ (respectively firm $B$ ) makes the discovery first and $F$ is the fixed cost that the follower must pay in order to achieve the level 
of technology of firm $A .{ }^{16}$ While the follower can conceivably enter the second stage of the race without pursuing any research, he is prevented from exploiting the innovation.

The payoffs to both firms when $d_{A}(h)=s$ are more complicated. In this setting, the winner of the asymmetric race is either the leader who makes the improvement, or the follower who makes the innovation. If the follower wins, the improvement has not been made yet, and then both firms are competing to be first to discover it and thus they are engaged in a new race. Therefore, the payoffs when $d_{A}(h)=s$ are

$$
\begin{aligned}
V_{s}^{A} & =\frac{1}{r}\left[-c \delta_{1}+p_{1} \Pi_{12}\left(1-\delta_{1}\right)+\left(1-p_{1}\right) r V_{2}^{A}\right] \text { for firm } A, \\
\text { and } V_{s}^{B} & =\frac{1}{r}\left[-c \delta_{1}+\left(1-p_{1}\right) r V_{2}^{B}\right] \text { for firm } B,
\end{aligned}
$$

where $V_{2}^{i}$ for $i=A, B$ is the payoff of firm $i$ once firm $B$ has made the innovation. To define $V_{2}^{i}$ precisely we need to consider the new decision of the follower: to patent the innovation or not $\left(d_{B / s} \in\{p, s\}\right)$. Recall that the considered patent system is "first-to-file," and thus the follower can enjoy a patent protection on the innovation, as he is first to file a patent application. ${ }^{17}$ If he decides not to patent it, the leader does not either as $p_{2} \geq 1 / 2$. Therefore, $V_{2}^{A}$ is defined as

$$
V_{2}^{A}= \begin{cases}\frac{1}{r}\left[-c\left(\delta_{2}-\delta_{1}\right)+p_{2} \Pi_{2}\left(1-\delta_{2}\right)\right] & \text { if firm } B \text { patents after catching up with firm } A \\ \frac{1}{r}\left[-c\left(\delta_{2}-\delta_{1}\right)+p_{2} \Pi_{12}\left(1-\delta_{2}\right)\right] & \text { if firm } B \text { does not }\end{cases}
$$

where $p_{2}$ represents the probability that firm $A$ makes the discovery, $\delta_{2}=1-e^{-r t_{2}}$, as the discovery is made at $t_{2}$. Firm $B$ gets

$$
V_{2}^{B}=\frac{1}{r} \max \left\{\left(\Pi_{1}-c\right)\left(\delta_{2}-\delta_{1}\right)+\left(1-p_{2}\right) \Pi_{2}\left(1-\delta_{2}\right),-c\left(\delta_{2}-\delta_{1}\right)+\left(1-p_{2}\right) \Pi_{12}\left(1-\delta_{2}\right)\right\},
$$

where the first term in the bracket represents his payoff if $d_{B / s}=p$ and the second term if $d_{B / s}=s$. A comparison of these two payoffs allows to determine whether or not the follower should patent. As we will see in the next section, for certain constellations of the parameters, the follower prefers to patent. We now define the payoffs when the innovation cannot be improved upon.

\footnotetext{
${ }^{16}$ Alternatively, one can imagine that firm $B$ must discover the innovation by himself, and $F$ is only an entry fee that the follower has to pay. In this case, his payoff becomes $V_{p}^{B}=\frac{1}{r}\left[-c \delta_{1}+(1-p) V_{2}^{B}\left(1-\delta_{1}\right)\right]-F$, where $V_{2}^{B}$ is the discounted expected profit of firm $B$ once he has caught up with $A$ and is precisely defined later.

${ }^{17}$ In the "first-to-invent" patent system, he would share the payoff with firm $A$, as firm $A$ was the first innovator.
} 


\subsection{Payoffs in the Case of a Non-Improvable Innovation}

Next, we consider a case where the innovation can have a positive value itself (i.e., $\Pi_{1}>$ 0) but cannot be improved (because, for instance, it is prohibitively costly to do so, or the improvement is not worthwhile). The leader continues her research program, but this time it is not for improving the innovation. To keep the model simple, we assume that the new innovation generates the same flow of payoff $\Pi_{1}$.

If the leader patents her non-improvable innovation $\left(d_{A}(l)=p\right)$, the follower must spend a fixed research cost in order to acquire the technology before trying to improve upon it. However, after spending this fixed cost, he learns that the innovation cannot be improved. At this point, he must decide whether to stay in the race or not; that is, whether to start a new project or not. The new innovation might use a portion of the previous production facilities; thus, the follower could decide to enter the race in order to recoup some of his fixed costs, and to costlessly explore other fields of research. ${ }^{18}$

If the leader decides to keep her innovation secret $\left(d_{A}(l)=s\right)$, the follower can pursue his research. If he makes the innovation eventually, he learns that the innovation cannot be successfully improved. He then has to decide whether or not to exploit this innovation, and continue the race to discover a new innovation.

If the follower exits the race, then his payoff is null, and firm $A$ gets

$$
R_{p}^{m}=\int_{0}^{+\infty} \Pi_{1} e^{-r t} d t-\int_{0}^{t_{1}} c e^{-r t} d t+\int_{t_{1}}^{+\infty} \Pi_{1} e^{-r t} d t=\frac{1}{r}\left[\Pi_{1}-c \delta_{1}+\Pi_{1}\left(1-\delta_{1}\right)\right]
$$

if she patents, and $R_{s}^{m}=\frac{1}{r}\left[-c \delta_{1}+\Pi_{1}\left(1-\delta_{1}\right)\right]$ if she keeps the innovation secret. Here, the second innovation does not invalidate the first one, and therefore, the patentholder can enjoy infinite-life patent protection. If the follower stays after a patent $\left(d_{B}(p)=\right.$ stay $)$, the payoffs are

$$
\begin{aligned}
R_{p}^{A} & =\frac{1}{r}\left[\Pi_{1}-c \delta_{1}+p_{1} \Pi_{1}\left(1-\delta_{1}\right)\right] \text { for firm } A, \\
\text { and } R_{p}^{B} & =\frac{1}{r}\left[-c \delta_{1}+\left(1-p_{1}\right) \Pi_{1}\left(1-\delta_{1}\right)\right]-F, \text { for firm } B
\end{aligned}
$$

If $d_{A}(l)=s$, either firm can win the race. If the leader is the winner, she has a new innovation and the game is over. If the winner is the follower, he has only discovered the initial innovation,

\footnotetext{
${ }^{18}$ The fixed cost is sunk at the time the discovery is made, but not at the time the decision is made to stay in the race or not.
} 
and a new race starts. The payoffs are

$$
\begin{aligned}
R_{s}^{A} & =\frac{1}{r}\left[-c \delta_{1}+p_{1} \Pi_{1}\left(1-\delta_{1}\right)+\left(1-p_{1}\right) r R_{2}^{A}\right], \\
\text { and } R_{s}^{B} & =\frac{1}{r}\left[-c \delta_{1}+\left(1-p_{1}\right) r R_{2}^{B}\right] .
\end{aligned}
$$

where the payoffs from competing in the second race are

$$
\begin{aligned}
R_{2}^{A} & =\frac{1}{r}\left[-c\left(\delta_{2}-\delta_{1}\right)+p_{2} \Pi_{1}\left(1-\delta_{2}\right)\right] \\
\text { and } R_{2}^{B} & =\frac{1}{r}\left[\Pi_{1}\left(1-\delta_{1}\right)-c\left(\delta_{2}-\delta_{1}\right)+\left(1-p_{2}\right) \Pi_{1}\left(1-\delta_{2}\right)\right]
\end{aligned}
$$

where $p_{2}$ represents the probability of firm $A$ making the discovery and $\delta_{2}=1-e^{-r t_{2}}$. In the case of a non-improvable innovation, on the equilibrium path, the follower always patents after catching up with the leader. As this is a dominant strategy for the follower $\left(d_{B / s}=p\right)$, we just write the equilibrium payoff.

Before solving the game under both symmetric and asymmetric information, we formally state restrictions on parameters. As we are mainly interested in the decision stage, we restrict the values of the parameters such that the gross payoffs are non-negative. If it was not the case, firms would just not participate in the races. Furthermore, we also put restrictions on the entry cost $F$ paid by the follower: this cost is assumed to be such that $V_{p}^{B}>0>R_{p}^{B}$. The entry cost does not allow the follower to make a positive profit when the innovation cannot be improved upon. These restrictions are summarized in the following lemma:

Lemma 1 The gross payoffs are non-negative if

$$
\begin{aligned}
& \Pi_{2}>K, \Pi_{12}>\Pi_{1}, \\
& \text { and } K>\Pi_{1}>\max \left\{\frac{\delta_{1}}{p_{1}\left(1-\delta_{1}\right)}, \frac{\left(\delta_{2}-\delta_{1}\right)}{\left(1-p_{2}\right)\left(1-\delta_{2}\right)}\right\},
\end{aligned}
$$

where $K \equiv\left(c \delta_{1}+r F\right) /\left(1-p_{1}\right)\left(1-\delta_{1}\right)$.

The formal proof of this lemma is given in the appendix. We impose lower bounds on $\Pi_{2}$ and $\Pi_{12}$ to make sure that the gross payoffs are positive and that the firms continue to search. In the rest of the paper we consider that the inequalities in (2) are always satisfied. 


\section{Symmetric Information}

As a benchmark, we consider the case of symmetric information in which both firms know whether the innovation can be improved or not. We analyze first the improvable innovation $(\Omega=h)$. To determine the Nash perfect equilibrium of the game, we solve the game backward; (a) we start with the very last decision of the follower (that actually does not appear in the decision stage, but later in the game) when the innovation has been kept secret and the follower has caught up with the leader, $\left(d_{B / s} \in\{p, s\}\right)$; (b) then, in the decision stage, we study the decision of the follower to stay or not $\left(d_{B} \in S_{B}\right) ;(c)$ and finally we consider the patenting decision of the leader $\left(d_{A} \in S_{A}\right)$. We now solve the game.

(a) If $\Omega=h, d_{A}(h)=s$, and the follower has caught up, he keeps it secret $\left(d_{B / s}=s\right)$ if he gets a higher profit from doing so. The comparison of the payoffs is given in the appendix and we obtain that the follower chooses $d_{B / s}=s$ if

$$
\Pi_{2}<\Pi_{12}-\frac{\left(\delta_{2}-\delta_{1}\right) \Pi_{1}}{\left(1-\delta_{2}\right)\left(1-p_{2}\right)} .
$$

Even though this last decision is made during the race stage, it has not to be omitted in order to have a complete specification of the equilibrium. This decision will not be altered by the information structure. Indeed, under asymmetric information it will be made while the follower has learnt whether the innovation is improvable. It is why this decision does not explicitly appear in the decision stage of the game.

(b) Now we turn to the decision of the follower to stay in the race or to exit $\left(d_{B} \in S_{B}\right)$. Whatever the strategy chosen by the leader, $d_{B}(\cdot)=$ stay as $V_{s}^{B}>0$ and $V_{p}^{B}>0$ if Lemma 1 is satisfied.

(c) Anticipating that the follower stays no matter what strategy she chooses, the leader's decision is $d_{A}(h)=s$ if $V_{s}^{A}$ (payoff from keeping the innovation secret) is greater than $V_{p}^{A}$ (payoff from patenting it). We can rewrite $V_{s}^{A}>V_{p}^{A}$ as

$$
\Pi_{2}<\Pi_{12}+\frac{\left(1-p_{1}\right) r V_{2}^{A}-\delta_{1} \Pi_{1}}{\left(1-\delta_{1}\right) p_{1}},
$$

where the value of $V_{2}^{A}$ depends on the equilibrium path after the follower has caught up with the leader (as defined in $(a)$ ) and is defined by one of the equations (1). 
Our first proposition follows:

Proposition 1 (Improvable innovation) If the innovation can be improved upon and the inequality (4) is satisfied, there exists a unique Nash perfect equilibrium such that (i) the leader decides to keep her innovation secret and (ii) the follower always stays in the race. If he catches up with the leader, he keeps it secret as long as (3) is satisfied; otherwise he patents it.

The proof of this proposition is partially given above, and partially in the appendix. All of the remaining proofs are given in the appendix.

If the inequality (4) is not satisfied, there exists a Nash perfect equilibrium such that the innovator always patents and the follower stays in the race. When the flow of payoff generated only by the improvement $\left(\Pi_{2}\right)$ is bigger than the flow of payoff from the improved innovation $\left(\Pi_{12}\right)$, the leader unambiguously patents her innovation, as the added value of the improvement created by the introduction of the innovation is worthwhile. At the other extreme, for values of $\Pi_{2}<<\Pi_{12}$, the leader keeps her innovation secret, as the introduction of the innovation is not profitable to the improvement. Those two sets of results are intuitive. However, when both $\Pi_{2}$ and $\Pi_{12}$ are large and close enough, the leader prefers to keep her innovation secret (even though we may have $\Pi_{2}>\Pi_{12}$ ). Hence, the leader may prefer to keep her competitive advantage in the race by not disclosing information through a patent.

We represent this result in a graph $\left(\Pi_{12}, \Pi_{2}\right)$, where we plot the right hand side of the inequalities (3) and (4). We also represent the lower bounds defined in (2).

\section{Insert Figure 1}

We fix the value of $\Pi_{2}$ and increase $\Pi_{12}$. At point $X$ the decisions of the firms are $d_{A}(h)=p$ and $d_{B}(p)=$ stay. As $\Pi_{12}$ increases, we reach an area where $d_{A}(h)=s$ and $d_{B}(s)=$ stay, but the follower patents as soon he catches up with the leader, i.e., $d_{B / s}=p$ (point $Y$ ). Then, if $\Pi_{12}$ increases again, the follower chooses $d_{B / s}=s$ (point $Z$ ).

Hence, if the payoff from waiting is worthwhile, the leader prefers to keep her competitive advantage and patent the improvement that gives higher payoff. The risk is that the follower 
catches up with her (with probability $1-p_{1}$ ) and makes the improvement with probability $\left(1-p_{2}\right)$ before her.

Therefore, under symmetric information, the leader decides to keep her innovation secret for two reasons: first, to maintain her competitive advantage of being ahead, and second, because the return to waiting is greater than the return to immediately patenting. The former case arises when $\Pi_{12}$ is small compared to $\Pi_{2}$, whereas the latter arises when $\Pi_{12}$ is large compared to $\Pi_{2}$.

In the case of a non-improvable innovation, the resolution is similar. It is a dominant strategy for the follower to always patent if he catches up while the innovation has been kept secret. We then determine the best response of the follower for any decision of the leader. As $\Pi_{1}<K$, firm $B$ does not stay if the leader patents the innovation, but stays otherwise. The leader

anticipates correctly what the follower will do, and then decides to always patent, as $R_{p}^{m}>R_{s}^{A}$. We summarize this second set of results in the following proposition:

Proposition 2 (Non-improvable innovation) If the innovation cannot be improved upon, there exists a unique Nash perfect equilibrium such that (i) the leader decides to patent her innovation, and (ii) the follower does not stay in the race.

This result is straightforward, as an innovation that needs not be kept secret (because it cannot be improved upon and does not generate any future payoff) will be patented, and it is not worthwhile for the follower to stay in the race.

\section{Asymmetric Information}

We now consider the case in which the follower does not know whether the innovation can be improved upon or not. We use the concept of Perfect Bayesian equilibrium to solve this game. As we introduce asymmetric information, we explicitly specify prior beliefs for the follower; before making his decision, with probability $\rho$ the follower believes that the innovation can be improved and with probability $(1-\rho)$ he believes that it cannot. In fact, he will only be aware of the improvability of the innovation after having made the innovation himself. However, after observing the strategy of the leader, the follower can update his beliefs according to Bayes' rule. 
We first investigate whether a separating equilibrium exists in which the leader patents the non-improvable innovation, and keeps secret the improvable innovation. Then, the mere observation of the patent informs the follower that the innovation cannot be improved upon. Therefore, his updated beliefs are such that the probability of having an improvable innovation when the leader keeps her innovation secret is one, whereas it is zero if it is patented. In other words, the strategy of the leader completely reveals her private information. This equilibrium exists so long as $V_{p}^{m}<V_{s}^{A}$, that we can rewrite as

$$
\Pi_{2}<p_{1} \Pi_{12}+\frac{\left(1-p_{1}\right) r V_{2}^{A}-\delta_{1} \Pi_{1}}{1-\delta_{1}}
$$

where the payoff $V_{2}^{A}$ is defined on the equilibrium path by (1). We can state our first result under asymmetric information:

Proposition 3 (Separating equilibrium) If (5) is satisfied, there exists a Perfect Bayesian equilibrium such that (i) the leader always keeps the innovation secret if it can be improved, but patents it otherwise; and (ii) the follower decides not to stay after a decision to patent, and stays after a decision to keep secret. In the latter case, if the follower catches up with the leader, he keeps the innovation secret as long as (3) is satisfied; otherwise he patents.

This result is consistent with the result obtained under symmetric information. If $\Pi_{12}$ is much bigger than $\Pi_{2}((5)$ is satisfied), the leader has no incentive to patent an improvable innovation. Hence, the decision to suppress signals with no ambiguity to the follower that the innovation can be improved upon. On the contrary, the patenting decision signals that the innovation cannot be improved.

This result no longer holds if the inequality (5) is not satisfied. Indeed, the leader will deviate from the equilibrium path as she can get a higher payoff if she patents the improvable innovation. We thus find different equilibria whenever the inequality (5) does not hold.

We first investigate whether a pooling equilibrium exists in which the leader patents regardless of whether the innovation can be improved or not. In this case, the updated beliefs of the follower remain equal to his prior beliefs, as he cannot infer anything from observing of the decision of the leader. In order to characterize this equilibrium, we define the value of the 
prior belief that makes the follower indifferent between staying and not, namely

$$
\rho^{*} \equiv \frac{r F+c \delta_{1}-\Pi_{1}\left(1-p_{1}\right)\left(1-\delta_{1}\right)}{\left(\Pi_{2}-\Pi_{1}\right)\left(1-\delta_{1}\right)\left(1-p_{1}\right)} .
$$

Depending on whether the value of the prior belief is larger or smaller than $\rho^{*}$, we characterize two different equilibria: one in pure strategies (the pooling equilibrium defined above) and one in mixed strategies (a hybrid equilibrium in which the leader randomizes her decision). We state our findings in the following proposition:

Proposition 4 If condition (4) is satisfied and (5) is not,

1. and $\rho<\rho^{*}$, there exists a Perfect Bayesian equilibrium in which (i) the leader always patents her innovation and (ii) the follower exits the race for any out-of-equilibrium beliefs $\mu$ (pooling equilibrium);

2. and $\rho \geq \rho^{*}$, there exists a Perfect Bayesian equilibrium in which (i) the leader randomizes her patenting decision when the innovation can be improved, while she always patents it when it cannot be improved; and (ii) the follower stays in the race when there is no patent, but then randomizes his exit decision when there is a patent (hybrid equilibrium).

Under symmetric information, if condition (4) is satisfied, the leader suppresses her innovation in order to keep her competitive advantage, even though she could get a higher payoff from introducing the innovation before attempting to improve upon it (if $\Pi_{2}>\Pi_{12}$, for instance). However, under asymmetric information and with pessimistic beliefs on behalf of the follower $\left(\rho<\rho^{*}\right)$, the leader prefers to patent her innovation before introducing the improvement. Because this strategy induces the follower to exit the race, the leader has a monopoly position for the exploitation of both the innovation and the improvement. In fact, the asymmetric information restores incentives for the leader to disclose her innovation through a patent. Conversely, this action provides no incentive for the follower to pursue the research. The patenting decision is therefore used by the leader to trigger the exit of the follower.

This contrasts with the case of symmetric information. With more optimistic beliefs on behalf of the follower $\left(\rho \geq \rho^{*}\right)$, he would prefer to stay in the race. In this case, there is still an 
attempt from the leader to precipitate the follower's exit by randomizing her patenting decision. Indeed, the leader prefers to randomize her decision in order not to reveal information to the follower. The patenting decision no longer signals a non-improvable innovation, whereas the non-patenting decision reveals that the innovation can be improved upon. Thus, the follower more often decides to exit, as he is not sure of the improvability of the innovation.

We represent the new equilibria in figure 2.

\section{Insert Figure 2}

As before, we fix $\Pi_{2}$, and increase $\Pi_{12}$. Surprisingly, at point $Z$ the leader prefers to patent under asymmetric information. The follower decides to exit with a probability less than 1 . At point $W$ the leader keeps her innovation secret and the follower stays in the race, as the secret signals an innovation that can be improved.

Hence, under asymmetric information the innovation is disclosed more often (through patenting), but the patenting is, in a sense, less informative and more often induces the exit of the follower (and thus, there is less research). The very purpose of patenting, the dissemination of knowledge to foster future research, is changed when there is asymmetric information. This result is consistent with the fact that firms do patent, but pretend not to rely on this type of IPRs to appropriate the return from their innovation. We summarize these findings in the following corollary:

Corollary 1 For a given $\Pi_{2}$, the patenting decision is locally non-monotonic as $\Pi_{12}$ increases, and the exit decision is also locally non-monotonic.

\section{Comparative Statics}

We now perform some comparative static analyses. We investigate how the equilibria vary after an increase in some of the key parameters of the model. We look at the impact of a change in the probability of winning, the date at which the discovery is made, and the discount rate.

If we start from a low $p_{1}$, holding all the other variables constant (with $t_{2}<t_{1}$ and $p_{2}$ large 
enough), we are in a situation represented by figure 3 .

\section{Insert Figure 3}

As $p_{1}$ increases, the whole graph moves towards the right and the downward functions become steeper. As $p_{1}$ increases the downward functions start to slope upwards, as is the case in figure 1 (or figure 2). Therefore, as $p_{1}$ increases, the area where the leader keeps the innovation secret shrinks, and the area where she patents expands. Note, however, that the lower bounds of $\Pi_{2}$ and $\Pi_{12}$ may also move after a change in $p_{1}$. Indeed, the lower limit for $\Pi_{2}$ is increasing with $p_{1}$, as can the lower limit for $\Pi_{12}$. For a given $\Pi_{12}$ low enough, as the probability of making first the discovery (the improvement) increases, the leader more often patents and does not need to keep her advantage of being the leader. On the contrary, if $p_{1}$ is small, the leader is better off keeping her advantage and, thus, more often suppressing her innovation.

If $\delta_{1}$ increases after an increase in the time to make the first discovery (innovation or improvement), the patenting area shrinks, as does the strategic patenting decision. Therefore, as catch up takes more time, the leader more often prefers to keep her innovation secret.

On the contrary, if $r$ increases, the patenting decision area expands, as the leader puts more weight on the present than on the future. We summarize these findings in the following corollary:

Corollary 2 Holding everything else constant,

- increasing the probability of winning for the leader induces her to patent more often;

- increasing the date on which the first discovery will occur induces the leader to patent (strategically or not) less often;

- increasing the discounting factor induces the leader to patent more.

In a more complex model of a patent race, the investments in $\mathrm{R} \& \mathrm{D}$ (here represented by the same fixed investment $c$ for each firm) have an impact both on the probability of discovery and the date on which the discovery is made. If the discovery process is a Poisson process, as is assumed in most of patent race literature, the expected date of discovery for firm $A$ becomes $E \tau_{A}=1 / \lambda\left(c_{A}\right)$, where $\tau_{A}$ is the random date of discovery of the improvement, $c_{A}$ the investment made by firm $A$, and $\lambda\left(c_{A}\right)$ is the instantaneous probability of discovering the innovation that is 
an increasing function of the investment. Therefore, the random date of discovery for either firm is $\tau=\min \left\{\tau_{A}, \tau_{B}\right\}$, where $\tau_{B}$ is the random date of discovery for firm $B$, and the expected date of discovery ( $t_{1}$ in our simplified model) is $E \tau=1 /\left(\lambda\left(c_{A}\right)+\lambda\left(c_{B}\right)\right)$, where $c_{B}$ is the investment of firm $B$. We can also determine $E\left(1-\delta_{1}\right)=E e^{-r \tau}=\left(\lambda\left(c_{A}\right)+\lambda\left(c_{B}\right)\right) /\left(\lambda\left(c_{A}\right)+\lambda\left(c_{B}\right)+r\right)$, $E\left(\delta_{1}\right)=1-E e^{-r \tau}=r /\left(\lambda\left(c_{A}\right)+\lambda\left(c_{B}\right)+r\right)$ and the probability of discovering the innovation $p_{1}=\lambda\left(c_{A}\right) /\left(\lambda\left(c_{A}\right)+\lambda\left(c_{B}\right)\right)$.

By increasing her intensity of research, firm $A$ reduces the length of the period during which she will do research for the improvement (because $E\left(\delta_{1}\right)$ is decreasing with $c_{A}$ ), and at the same time, increases her own chances of winning $\left(p_{1}\right)$. But at the same time, firm $B$ is likely to increase his investment; this has the opposite effect on firm $A$ 's probability of winning ( $p_{1}$ decreases with $c_{B}$ ) as well as decreasing the length of time during which both firms do research (because $E\left(\delta_{1}\right)$ is also decreasing with $c_{B}$ ). In fact, in the case of a more complex model of a race, it is impossible to hold everything else constant while looking at the effect of the change of one variable on the decision to patent and the decision to stay. Indeed, if firm $A$ increases her investment, firm $B$ increases his too (in this case the investments are endogenous choices), and this will impact the probability of winning, as well as the date on which the discovery will occur.

However, an increase in the discount factor has no impact on the probability of being the first to make a discovery, but increases the expected date on which it will occur. There are two effects: a direct effect and an indirect effect. The direct effect of an increase in the discount factor induces more patenting, whereas the indirect effect (through the expected date of discovery) induces less patenting. Therefore, it is not clear which effect dominates. Thus, in the case of a more complex model, it is difficult to reach a definitive conclusion regarding these comparative static exercises. However, the results we find above, with symmetric and asymmetric information, do hold in the more complex case.

\section{Conclusion}

This paper offers an explanation of the patenting behavior of firms beyond a simple cost-benefit approach. An innovator who has made a discovery must choose the most appropriate patenting 
date. Without any competition, she compares the discounted payoff from holding a patent if she patents her innovation immediately and the discounted payoff from holding a patent if she waits and patents it later. However, when competition is introduced, the leader (first innovator) more frequently decides to keep her innovation secret in order to keep her competitive advantage of being ahead in the race, even though the waiting decision entails risk. Indeed, if her rival catches up with her, he can patent or, at least, exploit the innovation instead of her. This is true as long as firms share the same information on whether the innovation can be improved. When the leader has more information concerning the improvability of the innovation, she can patent strategically, and thus she patents more frequently as she adopts a random behavior. This random patenting behavior makes her unpredictable, and her rival cannot gain any information from observing her decision, and will also randomly choose his action. Therefore, a patent that is supposed to signal an innovation that cannot be improved will sometimes be interpreted as a decoy, and the competitor will stay in the race, and thus be sent to an unprofitable field of research.

In a simplified model of race, we show that in the case of symmetric information, firms patent less frequently and stay in the race more often. This stimulates research but does not stimulate the disclosure of information through a patent. However, when the leader has more information than the follower concerning the improvability of the innovation, she may decide to patent strategically, in order to mislead her rival. Therefore, interestingly, in the case of asymmetric information, the leader will patent more frequently than in the case of symmetric information, whereas the follower will not pursue the research as often as previously. Thus, this stimulates the disclosure but not research.

In non-strategic models, research and disclosure tend to move together (if patents become longer, for instance). Our model predicts that in environments that are more asymmetric, we would expect to see increased disclosure (patenting), but possibly less follow-on research by competitors. This suggests that, for a policy change that increases the asymmetry in information, we might expect more patenting but no more (and possibly less) research. This is also argued by Hall and Ham-Ziedonis (2001) in the semi-conductor industry, but for a different reason: firms may use patents for strategic reasons as bargaining chips to avoid court cases. 
We have adopted a highly simplified model of a race. Indeed, as briefly mentioned in Sections 2 and 5, a more complex model of a patent race with the Poisson process of discovery would capture the two features not included in this model: the fact that there is uncertainty on the discovery date and on the identity of the winner, and that by choosing an intensity of research each firm can influence these two variables. The optimal choice of the intensity of research by each firm would have an impact both on the date of discovery and the probability of winning. The introduction of this new decision variable complicates the model without really changing the flavor of the results. The timing could be: first, firms make their decisions (exactly like in the previous setting, sequentially) and second, depending on what they have first decided, they simultaneously choose their research intensities. According to Grossman and Shapiro (1986, 1987), the intensity of research varies according to the position of the firms in the race. For instance, the leader intensifies her research when she is in competition with the follower, as opposed to the case where she is by herself in the race. Concerning the decision to patent and the decision to exit, the outcomes of the game are not very different from what we find in a much simpler setting.

\section{References}

[1] Aoki, R. and J.L. Hu. "Licensing versus Litigation: Effect of the Legal System on Incentive to Innovate," Journal of Economics and Management Strategy, 8:133-160 (1999).

[2] Chang, H. "Patent Scope, Antitrust Policy and Cumulative Innovation," RAND Journal of Economics, 26:34-57 (1995).

[3] Choi, J.P. "Technology Transfer with Moral Hazard," International Journal of Industrial Organization, 19:249-266 (2001).

[4] Cohen W., R. Nelson and J. Walsh. "Protecting their Intellectual Assets: Appropriability Conditions and Why US Manufacturing Firms Patent (or Not)," NBER Working Paper, $W 7552(2000)$. 
[5] Crampes, C. and C. Langinier. "Information Disclosure in the Renewal of Patents," Les Annales d'Economie et Statistique, 49/50:266-288 (1998).

[6] Crampes, C. and C. Langinier. "Litigation and Settlement in Patent Infringement Cases," RAND Journal of Economics, 33:228-274 (2002).

[7] Gallini, N. "The Economics of Patents: Lessons from Recent U.S. Patent Reform," Journal of Economic Perspectives, 16:131-154 (2002).

[8] Gallini N., J. Putnam and A. Tepperman. "Intellectual Property Rights and the Propensity to Patent," Prepared for the International Conference on Intellectual Property and Innovation in the Knowledge-based Economy (2001).

[9] Green, J.R and S. Scotchmer. "On the Division of Profit in Sequential Innovation," RAND Journal of Economics, 26(1):20-33 (1995).

[10] Grossman, G. and C. Shapiro. "Optimal Dynamic R and D Programs," RAND Journal of Economics, 17:581-594 (1986).

[11] Grossman, G. and C. Shapiro. "Dynamic R and D Competition," Economic Journal, 97:372-397 (1987).

[12] Hall, B. and R. M. Ham Ziedonis. "The Patent Paradox Revisited: Determinants of Patenting in the US Semiconductor Industry, 1979-95," RAND Journal of Economics, 32, No. $1: 101-128(2001)$.

[13] Hendricks, K. and R.P. McAfee. "Feints," mimeo (2003).

[14] Horstmann I., G.M. MacDonald and A. Slivinski. "Patents as Information Transfer Mechanisms: To Patent or (Maybe) Not to Patent," Journal of Political Economy, 93:837-858 (1985).

[15] Letcher, A. Successful Patents and Patenting for Engineers and Scientists. IEEE Press, 1995. 
[16] Matutes C., P. Regibeau and K. Rockett. "Optimal Patent Design and the Diffusion of Innovations," RAND Journal of Economics, 27:60-83 (1996).

[17] McKelvey, M.D. Evolutionary Innovations. Oxford University Press, 1996.

[18] Merger, R.P. and R.R. Nelson. "On Limiting or Encouraging Rivalry in Technical Progress: The Effect of Patent Scope Decisions," Journal of Economic Behavior and Organization, 25:1-24 (1994).

[19] O’Donoghue, T. "A Patentability Requirement for Sequential Innovation," RAND Journal of Economics, 29:654-679 (1998).

[20] O’Donoghue T, S. Scotchmer and J-J Thisse. "Patent Breadth, Patent Life, and the Pace of Technological Progress," Journal of Economics and Management Strategy, 7(1):1-32 (1998).

[21] Pakes, A. "Patents as Options: Some Estimates of the Value of Holding European Patent Stocks," Econometrica, 54:755-784 (1986).

[22] Reinganum, J. The Timing of Innovation. Handbook of Industrial Organization, 1989.

[23] Scotchmer, S. and J. Green. "Novelty and Disclosure in Patent Law," RAND Journal of Economics, 21:131-146 (1990).

[24] Takalo, T. and V. Kanniainen. "Do Patents Slow Down Technological Progress? Real Options in Research, Patenting, and Market Introduction," International Journal of Industrial Organization, 18:1105-1127 (2000).

[25] Van Dijk, T. "Patent Height and Competition in Product Improvements," Journal of Industrial Economics, 44:151-167 (1996). 


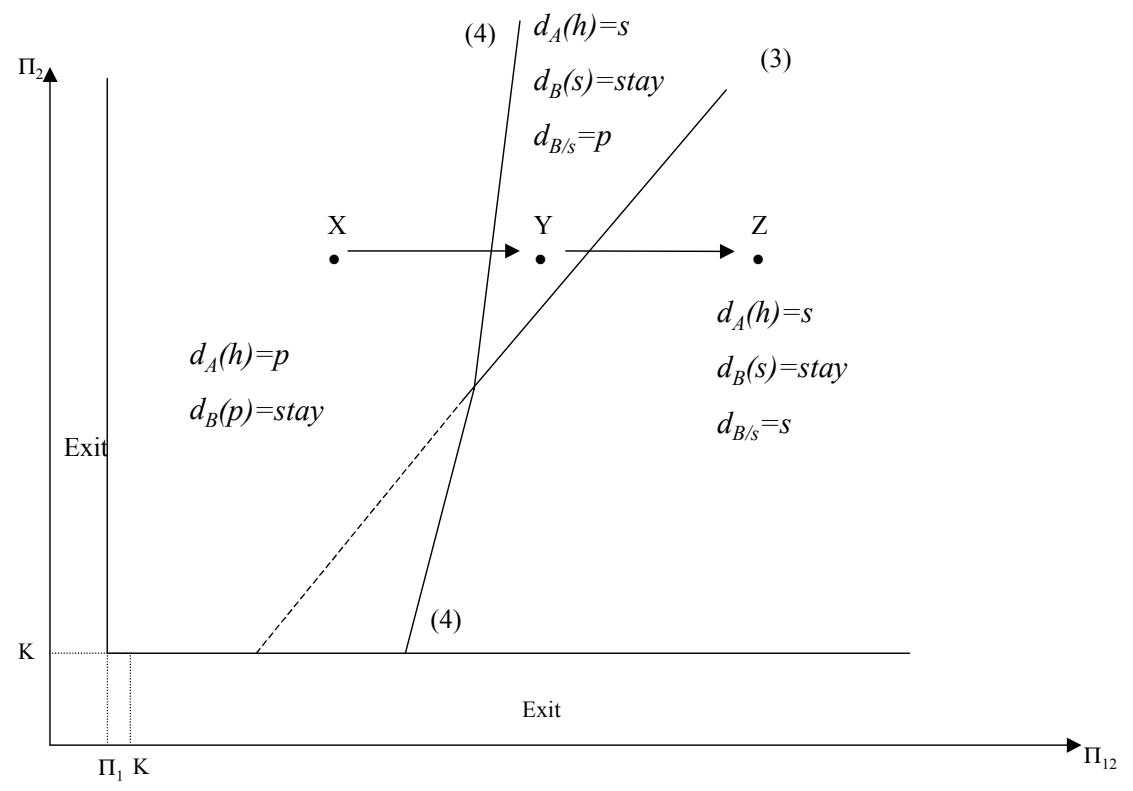

Figure 1: Patenting decision under symmetric information, with $p_{1}$ large enough

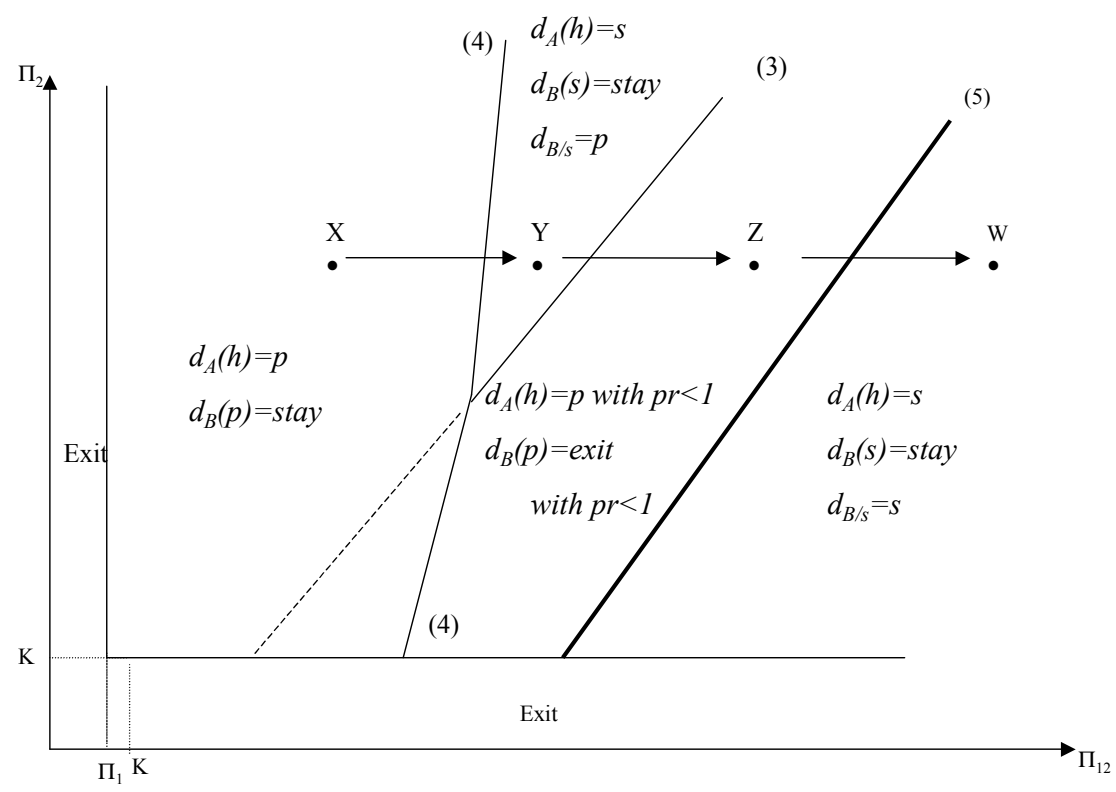

Figure 2: Patenting decision under asymmetric information, with $p_{1}$ large enough 


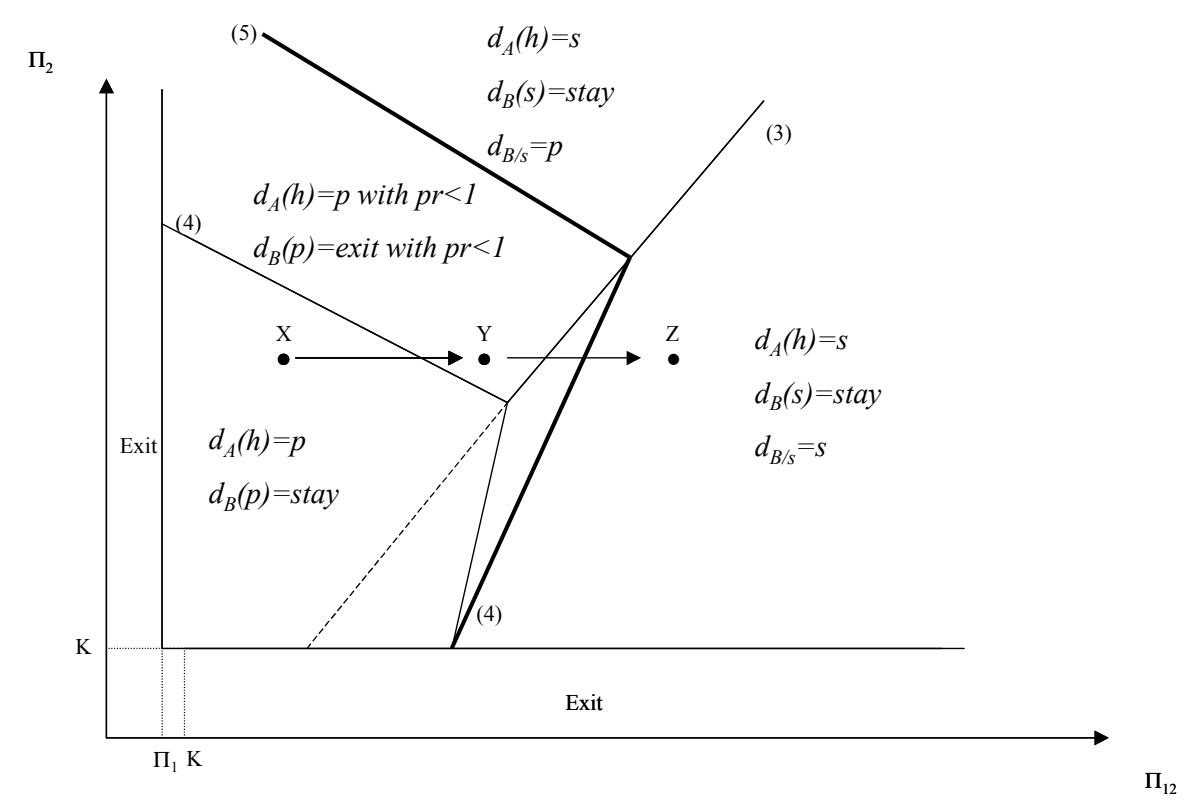

Figure 3: Patenting decision under asymmetric information, with $p_{1}$ small enough

\section{Appendix}

\section{Proof of Lemma 1}

The firms participate in the race if their payoffs are non-negative. When $\Omega=h$, and if $d_{A}(h)=p, V_{p}^{A}>0$ if $\Pi_{2}>\delta_{1}\left(c-\Pi_{1}\right) / p_{1}\left(1-\delta_{1}\right)$ and this implies that $V_{p}^{m}>0$. The follower chooses $d_{B}(p)=$ stay if $V_{p}^{B}>0$ which is equivalent to having $\Pi_{2}>K$ where $K=$ $\left(\delta_{1} c+r F\right) /\left(1-p_{1}\right)\left(1-\delta_{1}\right)$. If $d_{A}(h)=s, \Pi_{12}>\delta_{1} c / p_{1}\left(1-\delta_{1}\right)$ insures that she stays and it implies that $V_{s}^{m}>0$. If firm $B$ catches up with firm $A$, and patents the innovation $\left(d_{B / s}=p\right)$, $V_{2}^{A}>0$ if $\Pi_{2}>\left(\delta_{2}-\delta_{1}\right) c / p_{2}\left(1-\delta_{2}\right)$ or $\Pi_{12}>\left(\delta_{2}-\delta_{1}\right) c / p_{2}\left(1-\delta_{2}\right)$, and $V_{2}^{B}>0$ if $\Pi_{2}>$ $\left(\delta_{2}-\delta_{1}\right)\left(c-\Pi_{1}\right) /\left(1-p_{2}\right)\left(1-\delta_{2}\right)$ or $\Pi_{12}>\left(\delta_{2}-\delta_{1}\right) c /\left(1-p_{2}\right)\left(1-\delta_{2}\right)$. As we assume that $p_{2}>1 / 2$, the last condition on $\Pi_{12}$ implies $\Pi_{12}>\left(\delta_{2}-\delta_{1}\right) c / p_{2}\left(1-\delta_{2}\right)$.

When $\Omega=l$ and if $d_{A}(l)=s, \Pi_{1}>\delta_{1} c /\left(1-\delta_{1}\right) p_{1}$ insures that firm $A$ stays. Hence, it implies that $R_{p}^{A}>0$, as well as $R_{s}^{m}>0$ and $R_{p}^{m}>0$. If firm $B$ catches up with firm $A, R_{2}^{B}>0$ if $\Pi_{1}>\left(\delta_{2}-\delta_{1}\right) c /\left(1-\delta_{2}\right)\left(1-p_{2}\right)$ and it implies that $R_{2}^{A}>0$. And because the fixed cost $F$ is large enough, $R_{p}^{B}<0$ for $\Pi_{1}<K$. These conditions are summarized in Lemma 1. 


\section{Symmetric information Case}

Proof of Proposition 1: Improvable innovation $(\Omega=h)$

If firm $B$ discovers the innovation when $d_{A}(h)=s$, he chooses $d_{B / s}=s$ if $\Pi_{2}<\Pi_{12}-\left(\delta_{2}-\right.$ $\left.\delta_{1}\right) \Pi_{1} /\left(1-\delta_{2}\right)\left(1-p_{2}\right)$ as long as firm $A$ does not patent it afterwards. She will not patent it if $\Pi_{2}<\Pi_{12}-\left(\delta_{2}-\delta_{1}\right) \Pi_{1} / p_{2}\left(1-\delta_{2}\right)$. If $p_{2}>1 / 2$ (respectively $\left.p_{2}<1 / 2\right)$, then as long as $\Pi_{2}<\Pi_{12}-\left(\delta_{2}-\delta_{1}\right) \Pi_{1} / p_{2}\left(1-\delta_{2}\right)$ (respectively $\left.\Pi_{2}<\Pi_{12}-\left(\delta_{2}-\delta_{1}\right) \Pi_{1} /\left(1-\delta_{2}\right)\left(1-p_{2}\right)\right)$, none of the firm will patent after having discovered the innovation. This gives equation (3). The rest of the proof in given in the text above Proposition 1.

Proof of Proposition 2: Non-improvable innovation $(\Omega=l)$

When $d_{A}(l)=p$, firm $B$ is better off by exiting the race as $R_{p}^{B}<0$. On the other hand, if $d_{A}(l)=s$, firm $B$ chooses $d_{B}(s)=$ stay as $R_{s}^{B}>0$. Firm $A$ makes her decision according to the best response function of firm $B$. Therefore firm $A$ gets a higher payoff from patenting. The Nash Perfect equilibrium is such that firm $A$ patents and firm $B$ exits the race.

\section{Figures 1 and 3}

First, we define the lower boundaries of the functions. For low values of $\Pi_{12}\left(\Pi_{12}<\Pi_{1}\right)$ and $\Pi_{2}\left(\Pi_{2}<K\right)$, firms do not invest in the race. We then represent the different areas that represent the equilibrium. As $p_{2}>1 / 2$, the leader never patents the innovation after having been caught up by the follower if he has not patented the innovation. ${ }^{19}$ The inequality (3) becomes $\Pi_{2}<\Pi_{12}-\left(\delta_{2}-\delta_{1}\right) \Pi_{1} /\left(1-\delta_{2}\right) p_{2}$. We represent the right-hand side of this inequality in figure 1 (and figures 2 and 3 as well) that we call (3) as well.

(i) If this inequality is not satisfied (thus on the left of the function (3) in the figures), firm $B$ prefers to patent the innovation if he catches up with firm $A\left(d_{B / s}=p\right)$. In this case, firm $A$ 's decision is $d_{A}(h)=s$ if (4) is satisfied, where $V_{2}^{A}$ takes the value defined in (1). Therefore, the inequality (4) becomes $\Pi_{2}\left[\left(1-\delta_{1}\right) p_{1}-\left(1-p_{1}\right) p_{2}\left(1-\delta_{2}\right)\right]<\left(1-\delta_{1}\right) p_{1} \Pi_{12}-\left(1-p_{1}\right) c\left(\delta_{2}-\delta_{1}\right)-\delta_{1} \Pi_{1}$. The sign of $\phi=\left[\left(1-\delta_{1}\right) p_{1}-\left(1-p_{1}\right) p_{2}\left(1-\delta_{2}\right)\right]$ determines whether the function is downward or upward sloping.

\footnotetext{
${ }^{19}$ The case where $p_{2}<1 / 2$ is treated in a similar manner except that the leader can decide to patent her innovation once she has been caught up. This can be interpreted as a delay strategy for the leader. We do not consider in detail this case because the range of values for which the leader may delay her patenting decision is very small and has only a negligible role.
} 
(a) If $\phi>0$, the inequality (4) becomes $\Pi_{2}<\left[\left(1-\delta_{1}\right) p_{1} \Pi_{12}-\left(1-p_{1}\right) c\left(\delta_{2}-\delta_{1}\right)-\Pi_{1}\right] / \phi$ and the right side is represented by the line on the left of the function (3) in figure 1. This arises if $p_{1}>1 / 2$ (i.e., if $p_{1}$ is large enough). Indeed, because $\left(1-\delta_{1}\right)>\left(1-\delta_{2}\right)$ is always true (as $\left.t_{2}>t_{1}\right),\left(1-\delta_{1}\right)>\frac{1-p_{1}}{p_{1}} p_{2}\left(1-\delta_{2}\right)$ is always satisfied if $p_{2}<\frac{p_{1}}{1-p_{1}}$ which is true if $p_{1}>1 / 2$.

(b) On the contrary if $\phi<0$, the inequality (4) becomes $\Pi_{2}>\left[\left(1-\delta_{1}\right) p_{1} \Pi_{12}-\left(1-p_{1}\right) c\left(\delta_{2}-\right.\right.$ $\left.\left.\delta_{1}\right)-\Pi_{1}\right] / \phi$ and is represented on the left area in figure 3. This last case arises if $p_{1}$ is small enough. Indeed, a necessary condition to have $\left(1-\delta_{1}\right)<\frac{1-p_{1}}{p_{1}} p_{2}\left(1-\delta_{2}\right)$ is that $p_{1}<1 / 3$. We have thus defined in figures 1 and 3 the areas where the leader patents or keep her innovation secret when firm $B$ patents if he catches up with firm $A$.

(ii) If the inequality (3) is satisfied (in the right part of the three graphs), the inequality (4) evaluated at $(1)$ becomes $\Pi_{2}<\left[\left(\left(1-\delta_{1}\right) p_{1}+\left(1-p_{1}\right) p_{2}\left(1-\delta_{2}\right)\right) \Pi_{12}-\left(1-p_{1}\right) c\left(\delta_{2}-\delta_{1}\right)-\right.$ $\left.\delta_{1} \Pi_{1}\right] /\left(1-\delta_{1}\right) p_{1}$ and is represented in the right of $(3)$ in the three graphs.

\section{Asymmetric information: Perfect Bayesian Equilibrium}

There are two states of Nature, $\Omega=\{l, h\}$. Firm $B$ has only prior beliefs concerning these states of Nature: with probability $\rho$ he believes the innovation can be improved upon.

\section{Proof of Proposition 3}

We determine the separating equilibrium in which the leader patents her innovation when it cannot be improved $\left(d_{A}(l)=p\right)$ and keeps it secret otherwise $\left(d_{A}(h)=s\right)$. In this case, firm $B$ updates his beliefs, and can perfectly infer the improvability of the innovation after observing the decision made by firm $A$. After observing a patent, he exits the race as $\operatorname{Pr}[l /$ patent $]=1$. Therefore he exits after observing a patent, and stays in the race otherwise. The leader will deviate (from the equilibrium path) if $V_{s}^{A}<V_{p}^{m}$ and $V_{s}^{A}<V_{p}^{A}$. The last inequality does not hold if (4) is satisfied, and as long as (5) is satisfied, the former inequality does not hold either. Thus the leader does not deviate and this is an equilibrium. No other separating equilibrium exists.

\section{Proof of Proposition 4}

We then determine the pooling equilibrium when firm $A$ decides to patent her innovation whatever its improvability. Firm $B$ cannot infer any information from the observation of a patent, and his posterior beliefs are equal to his prior beliefs, $\operatorname{Pr}[l / p]=\frac{1-\rho}{\rho+(1-\rho)}=1-\rho$. He 
prefers to abandon the race as long as $\rho V_{p}^{B}+(1-\rho) R_{p}^{B}<0$ or in other terms as long as $\rho<\rho^{*}$ where $\rho^{*}$ is defined by equation (6). We also need to define what is the strategy of the follower off the equilibrium path. Whatever the improvability of the innovation, if the leader keeps her innovation secret, the follower always stays in the race. Therefore, the leader will not deviate if $V_{s}^{A}<V_{p}^{m}$ for values of $\rho$ such that $\rho<\rho^{*}$. Furthermore $V_{s}^{A}<V_{p}^{m}$ is equivalent to no (5). Thus, formally the pooling equilibrium is defined by $(i)$ the strategy of the leader for each type of innovation: $\left(d_{A}(h)=p, d_{A}(l)=p\right) ;(i i)$ the strategy of the follower when he observes the leader's strategy $\left(d_{B}(p)=\right.$ exit, $d_{B}(s)=$ stay $)$; $(i i i)$ the follower's belief is the prior belief $\rho$ that must be smaller than $\rho^{*}$; and $(i v)$ for any out-of-equilibrium belief $\operatorname{Pr}[h / s] \in[0,1]$.

So long as inequality (4) is satisfied, there is no other equilibrium in pure strategies. If this inequality (4) does not hold anymore, the only equilibrium that exists is a pooling equilibrium in which the leader always patents, and the follower stays or exits according to his prior beliefs.

We have defined equilibria in pure strategies. However, it also exist equilibria in mixed strategies as long as inequality (4) is satisfied. We define an equilibrium in which the leader always patents the non-improvable innovation whereas she randomizes her patenting decision of the improvable innovation. She patents with probability $q_{1}$ and keeps it secret with the complementary probability $\left(1-q_{1}\right)$. If the follower does not observe a patent, it is because the innovation can be improved and then he stays in the race. If he observes a patent, he does not know whether the innovation can be improved or not. When $\Omega=h$ the leader is indifferent between patenting it or not. There exists a probability $\eta=\operatorname{Pr}[\operatorname{stay} / p]$ such that $\eta V_{p}^{A}+(1-\eta) V_{p}^{m}=V_{s}^{A} \Rightarrow \eta=\left(V_{s}^{A}-V_{p}^{m}\right) /\left(V_{p}^{A}-V_{p}^{m}\right)$ where $\eta<1$ and $\eta>0$ if $V_{s}^{A}<V_{p}^{m}$ (condition non (5)). If $d_{B}(p)=$ stay, the follower's payoff is $\mu(h / p) V_{p}^{B}+(1-\mu(h / p)) R_{p}^{B}$ and it is equal to zero otherwise. He is indifferent between staying in the race or abandoning if $\mu(h / p)=\frac{-R_{p}^{B}}{V_{p}^{B}-R_{p}^{B}}$ where $R_{p}^{B}<0$. So, $\frac{-R_{p}^{B}}{V_{p}^{B}-R_{p}^{B}}=\frac{q_{1} \rho}{q_{1} \rho+(1-\rho)} \Rightarrow q_{1}=\frac{(1-\rho)}{\rho} \frac{-R_{p}^{B}}{V_{p}^{B}}$. This is satisfied for $\rho \geq \rho^{*}$.

The leader's choice to randomize her patenting decision when $\Omega=l$ cannot be an equilibrium. It is because she prefers to always patent in this case, and cannot be indifferent between patenting and not. 


\section{Figures 2 and 3}

(i) In figure 2, we represent the outcomes under asymmetric information on top of those under symmetric information derived in figure 1. In the left side of the graph (which corresponds to the case where $d_{B / s}=p$ ) things remain unchanged when $p_{1}>1 / 2$ (figure 2 ). In fact the right-hand side of the inequality (5) evaluated at the equilibrium value of $V_{2}^{A}$ does not appear in this part of the graph. On the contrary, in the right side of the graph, we can represent function (5) that is the right-hand side of inequality $(5): \Pi_{2}<\left[\left(\left(1-\delta_{1}\right) p_{1}+\left(1-p_{1}\right) p_{2}\left(1-\delta_{2}\right)\right) \Pi_{12}-\left(1-p_{1}\right)\left(\delta_{2}-\right.\right.$ $\left.\left.\delta_{1}\right) c-\delta_{1} \Pi_{1}\right] /\left(1-\delta_{1}\right) p_{1}$. This new equation is less steep than (4), and is on the right of (3).

(ii) Consider figure 3, when $p_{1}$ is small enough. In the left part of the graph, in the area where $d_{B / s}=p$, inequality (5) is represented by a downward function that lies above (4). It is the same in the right part of the figure, where the new inequality (5) lies above (4). Overall, it means that the area where the leader patents her innovation expends. Therefore, under asymmetric information, the leader patents more often. This in turn affects the decision of the follower to stay in the race. With a certain probability he will prefer to exit the race. 